\title{
Substance Abuse* and Employment Among Welfare Mothers: From Welfare to Work and Back Again?
}

\author{
LAURA SCHMIDT, ${ }^{1}$ DENISE ZABKIEWICZ, ${ }^{2}$ \\ LAURIE JACOBS $^{3}$ AND JIM WILEY $^{4}$
}

\author{
${ }^{1}$ Institute for Health Policy Studies and Department of Anthropology, History \\ and Social Medicine, University of California at San Francisco, San Francisco, \\ California, USA \\ ${ }^{2}$ Department of Epidemiology, University of California at Berkeley and Alcohol \\ Research Group, Public Health Institute, Emeryville, California, USA \\ ${ }^{3}$ Alcohol Research Group, Public Health Institute, Emeryville, California, USA \\ ${ }^{4}$ Public Research Institute and Department of Sociology, San Francisco \\ State University, San Francisco, California, USA
}

\begin{abstract}
We have very little research on how substance use impacts employment among welfare mothers. But welfare reform's emphasis on moving aid recipients into the workforce has brought this issue to the fore. Using Cox proportional hazard and logistic regression in a longitudinal study of California welfare mothers in 2001-2003, we examine how substance use impacts the ability to move from welfare to work and to remain economically independent after welfare. While education, work history, and family size consistently predict transitions from welfare to work and back again, substance use-related problems consistently do not. However, the jobs obtained by welfare mothers are short-term and poorly paid regardless of whether they misuse alcohol or use drugs. We argue that, if all that is open to welfare mothers are short-lived work assignments, substance use may have little time to impact job retention. Limitations of the study are noted. This IRB-approved study was supported by a grant from the National Institute on Alcohol Abuse and Alcoholism.
\end{abstract}

Keywords welfare; welfare reform; employment; unemployment; substance use; alcohol; drugs; women

\section{Introduction}

It is perhaps not surprising that we have very little in the way of a research track record on employment among welfare mothers. After all, up until quite recently, if such women were employed at all, the work was likely to be off-the-books, unsteady, and seldom reported to researchers, given that it constituted "welfare fraud" (Edin and Lein, 1997). This state of affairs, however, changed with the advent of federal welfare reform in 1996. With welfare

Address correspondence to Dr. Laura Schmidt, Ph.D., Institute for Health Policy Studies and Department of Medical Anthropology, History, and Social Medicine, University of California, San Francisco, Box 0936, 3333 California Street, Suite 265, San Francisco, CA 94118. E-mail: laura.schmidt@ucsf.edu

*The journal's style utilizes the category substance abuse as a diagnostic category. Substances are used or misused; living organisms are and can be abused. Editor'snote. 
reform, ${ }^{1}$ America took the unprecedented step of placing routine work requirements on most federal aid recipients, including those with young children in the home. Welfare reform's emphasis on "work first" has thus opened up a host of new issues surrounding work, family, education, and barriers to employment among women in poverty. Among these are provocative research questions concerning the relationships between substance use and unemployment among low-income women. This study addresses some of the core questions in this emerging debate. We examine the extent to which substance use impacts the ability of welfare mothers to move from welfare to work and then to remain economically independent during life after welfare.

The broader literature paints a rather complex picture of the relationships between substance use and employment. While it seems logical that substance use and misuse impact many dimensions of employment, prior studies offer surprisingly little direct evidence of consistent findings on wages and other labor market outcomes (Kaestner, 1998). Major studies, such as those based on the National Household Survey on Drug Abuse, have found no statistical relationship between drug use and being employed (United States Substance Abuse and Mental Health Services Administration, Office of Applied Studies, 1999), although they find a statistically significant association between long-term drug use and reduced wages (Bryant, Samaranyake, and Wilhite, 2000). Similarly, while some studies report that alcohol consumption diminishes on-the-job productivity (Ettner, 1997), others find that it may actually be beneficial for work productivity, particularly at more moderate levels of consumption (Berger and Leigh, 1988; French, Zarkin, Hubbard, and Rachal, 1991). It is an unfortunate fact that most of these prior studies have focused on samples of men. The extent that their findings apply to populations of women in poverty is essentially unknown.

We find more consistent results across studies that focus on the relationships between substance use and patterns of long-term, chronic unemployment. These studies suggest that substance use may have more impact on the capacity to keep a stable job than on the capacity to get one in the first place. Numerous studies show that longer periods of unemployment, and especially episodic, unsteady employment patterns, are strongly associated with increased alcohol and drug consumption and related problems (Claussen, 1999; Jin, Shah, and Svoboda, 1995; Kandel, Davies, Karus, and Yamaguchi, 1986; Lahelma, Kangas, and Manderbacka, 1995; Peck and Plant, 1986). Furthermore, work performance has been found to decline with substance use over time (French and Zarkin, 1995). Illicit drug use, in particular, has been associated with high rates of job turnover and decreased tenure (Dion, Derr, Anderson, and Pavetti, 1999; Kandel and Yamaguchi, 1987).

One finds interesting parallels in the small-but-growing body of literature on substance use in the welfare population. Here, a number of studies underscore the potential for substance use to impact job retention and job stability, after controlling for other important factors in employment. Cross-sectional studies of welfare recipients suggest that those with substance use-related problems are equally as likely to obtain work as other recipients but that their employment histories are less steady over time (Brooks and Buckner, 1996; Metsch, McCoy, Miller, McAnany, and Pereyra, 1999; Pavetti, Olson, Pindus, Pernas, and Isaacs, 1996). In longitudinal studies, drug use among women on Temporary Aid to Needy Families (TANF) has been associated with a decrease in the number of hours worked (Atkinson, Whitsett, et al., 2003). Others have found that, as compared with other aid recipients, substance users are more susceptible to patterns of repeat, on-and-off welfare use over time, or welfare cycling - a pattern of welfare dependence that is consistent with a pattern of unsteady, episodic employment (Schmidt, Dohan, Wiley, and Zabkiewicz, 2002; 
Schmidt, Weisner, and Wiley, 1998). A key limitation with welfare population studies is that sample sizes of recipients with alcohol and drug problems are often prohibitively small, given that the base rates of alcohol and drug problems among welfare mothers are relatively low (Schmidt and McCarty, 2000). Researchers may be forced to group recipients manifesting substance use-related and mental health problems together or to avoid independently addressing substance use at all (e.g., Danziger et al., 2000). Unless they collect extremely large samples, or sample substance users at disproportionately higher rates than other aid recipients, welfare researchers are unlikely to have sufficient sample sizes to conduct very reliable and refined analyses.

The existing literature leads us to hypothesize that a person's substance use operates as a barrier to leaving welfare for a job and, perhaps to an even greater extent, diminishes the capacity to maintain stable employment and economic independence from welfare over time. To address these questions in this study, we draw on three waves of longitudinal data from the Welfare Client Longitudinal Study (WCLS), collected between 2001 and 2003. The WCLS includes detailed information about welfare mothers' transitions on and off of the federal welfare program, TANF, including month-by-month accounts of how long they stayed on aid, how long they remained employed after leaving welfare, information on the characteristics and quality of the jobs they obtained and the reasons that some later returned to the welfare system. The WCLS further facilitates this analysis by including an oversample of aid recipients with alcohol- and drug use-related problems, which allows for more in-depth analyses of how substance use, along with many other influential factors, impacts welfare and work trajectories than have heretofore been possible.

\section{Methods}

The Welfare Client Longitudinal Study (WCLS) is an in-depth study following the impact of welfare reform on low-income substance users in a large California county. The project includes representative samples of cash aid applicants and recipients throughout the study site, including the large female population on TANF as well as single adults on local general assistance (GA). Study participants were first interviewed as they applied for aid in 2001 and are subsequently being followed and re-interviewed annually over 4 years. For the purposes of this analysis focused on welfare mothers, we analyze data on only those study participants who were female, who received TANF only and not GA, and who were included in the follow-up sample. (For selected publications on the WCLS, see: Dohan, Schmidt, and Henderson, 2005; Henderson, Dohan, and Schmidt, 2006; Schmidt et al., 2002, 1998, 2006).

\section{Sample}

Throughout, we use terms such as welfare mothers and substance abuse/use as loose indicators of groups included in our analysis. However, these labels should not be reified, given that they fail to capture the considerable heterogeneity within the categories of persons being labeled. Such heterogeneity within the category of welfare mothers is exemplified by the sample characteristics shown in Table 1 . The sample consists of 419 women with children, a subset of the WCLS study panel. These women applied for and received TANF aid in a large northern California county. As seen in Table 1, this is an ethnically diverse sample, with the majority of the women identifying their ethnicity as either African American, Latina, or other. Overall, the women in this sample tend to be relatively young single parents with two or fewer children at home. Most of them completed a high school education and have 
Table 1

Sample description

$\begin{array}{lr}\text { Mean age (years) } & 29.2 \\ \text { Ethnicity (\%) } & 29.2 \\ \text { White/Caucasian } & 38.1 \\ \text { Black/African-American } & 19.0 \\ \text { Latino/Hispanic } & 13.7 \\ \text { Other } & 22.7 \\ \text { Percent married or living with a partner } & 33.7 \\ \text { Percent with 3 or more children in the home } & 69.5 \\ \text { Percent graduated from high school } & 23.8 \\ \text { Percent with no work history within 12 months of baseline } & 78.2 \\ \text { Percent with a history of previous welfare use } & 30.1 \\ \text { Percent manifesting psychiatric distress } & 14.8 \\ \text { Percent manifesting substance use } & \end{array}$

Note. Unweighted $N=419$. Data are weighted for nonresponse and design.

recent work experience, and most of them have received welfare at least once before. A breakdown of some of these characteristics by substance use status can be found in Table 2, discussed later.

\section{Study Site}

The study site for the WCLS is a large, diverse northern California county, selected for its wide variation in ethnic and income groups. In addition to more affluent communities, the study site includes pockets of urban ghetto poverty as well as rural depressed areas.

Table 2

Baseline work-readiness of welfare mothers with and without substance use-related problems

\begin{tabular}{lcc}
\hline & Substance abuse & $\begin{array}{c}\text { No substance } \\
\text { abuse }\end{array}$ \\
\hline $\begin{array}{l}\text { Percent without work } \\
\text { history in last 12 months }\end{array}$ & 30.6 & 22.3 \\
$\begin{array}{l}\text { Percent high school } \\
\text { graduate }\end{array}$ & 59.7 & $71.2^{*}$ \\
$\begin{array}{l}\text { Percent with 3 or more } \\
\text { children in the home }\end{array}$ & 34.9 & 33.6 \\
$\begin{array}{l}\text { Percent manifesting } \\
\text { psychiatric distress }\end{array}$ & 55.6 & $42.2^{*}$ \\
$\begin{array}{l}\text { Mean age } \\
\text { Unweighted } N\end{array}$ & 28.4 & 29.3 \\
\hline
\end{tabular}

Note. Data are weighted for non-response and design. ${ }^{*} p \leq .05$. 
Characteristics of the welfare system also make this a suitable site for the WCLS. The county is the unit of government from which health and welfare services are delivered in most states, including in California. Moreover, upon implementation of welfare reform in 1997, the county welfare administration officially adopted the standard "work first" model and all of the most common welfare reform policies for targeting substance use-related problems in the caseload, including the exclusion of drug user felons from aid receipt and welfare check sanctioning for noncompliance with treatment and work programs. Finally, this site has been the setting for numerous published studies, having served as a "community laboratory" for population-based research on substance use and addiction since the 1980s (Caetano, 1991; Weisner and Schmidt, 1992, 1993, 1995a, 1995b). These prior site-specific studies provide a backdrop of knowledge about services for and trends in substance use throughout the study site. For example, rates of alcohol and drug use-related problems in the study site's welfare population are similar to comparable national and regional populations (see Schmidt and McCarty, 2000), which speaks to the broader generalizability of study results.

\section{Study Design}

At baseline in 2001, adult welfare applicants were systematically sampled, taking every $n$th welfare applicant from the daily intake rosters at all seven of the study site's welfare offices. In-person interviews with selected participants took place either before or after the welfare intake interview and always preceded the final determination of acceptance onto aid. We drew an initial sample of 1786 welfare applicants, among whom 1510 were successfully interviewed, yielding a baseline response rate of $85 \%$. Study participants were subsequently followed in welfare department records to determine which applicants ultimately received aid and which did not.

Of the 1510 welfare applicants interviewed in 2001, 63\% $(N=955)$ were later accepted onto aid. This group of 955 aid recipients became the sampling frame for the longitudinal portion of the WCLS. Given the expense of following low-income populations, we selected a random subsample of 718 aid recipients for annual tracking and interviews over a 4-year follow-up period. The follow-up sample includes an oversample of TANF recipients with alcohol and drug problems $(n=167)$ because their rates of substance use-related problems tend to be relatively low (Metsch and Pollack, 2005). Intensive tracking efforts have allowed us to successfully locate and re-interview $86 \%$ of this sample for the 12-month follow-up interview and $85 \%$ for the 24 -month follow-up interview. The overall refusal rate is below $2 \%$ and the mortality rate is $2 \%$.

\section{Procedures}

At baseline and each wave of follow-up, we conduct structured survey interviews in English and Spanish using professional survey interviewers and identical survey instruments. At baseline, face-to-face interviews were conducted in private places within welfare offices or in adjacent private locations. At each wave of annual follow-up, participants were interviewed by telephone if possible, but those without phones or who could not otherwise be reached were interviewed in-person in a variety of private locations, including their homes, jails, prisons, treatment facilities, shelters, and even parks in cases where study participants were homeless. The field team used an intensive, community-based field tracking approach to maintain contact with the WCLS sample. This involved regular searches of welfare and 
other public records, DMV and postal searches, extensive phone calling of contacts provided by study participants, and in-person visits to households, workplaces, "hangouts" and the homes of study participants and contact people. Less than $5 \%$ of the sample was located after having missed a prior interview. These individuals received an expanded interview that covers data from the missing interview asked retrospectively.

Special provisions were made to clearly distinguish interviewers from welfare department staff, to clarify that participation in the study was completely voluntary and had no bearing on the receipt of aid, that individuals could withdraw from the study at any point in time, and that the interview would be completely private. All study participants gave informed consent, and the project has received full approval from the institutional review boards at the Public Health Institute and University of California at San Francisco. In addition, study participants are protected by a federal certificate of confidentiality.

\section{Measures}

The measures used in this analysis are summarized in Appendix A. Dependent variables pertain to exits from the baseline period of TANF receipt, reentry following an initial welfare exit, and work-related reasons for exit and reentry. We collected self-report data on periods of aid receipt and employment using the timeline follow-back (TLFB) technique. TLFB uses memory-triggering events to help aid survey respondents in recalling events in their lives. This is a reliable method for reconstructing personal histories of substance use and other experiences over the lifespan (Sobell, Brown, Leo, and Sobell, 1996) and has been used in at least one prior study of substance use and unemployment (Kandel and Yamaguchi, 1987). At each interview, respondents are presented with a calendar of the past year upon which are entered memory-triggering events (e.g., birthdays, accidents, special occasions). Following a series of standard probes, interviewers then enter a month-by-month record of welfare use and employment, using the memory triggers to help respondents recall timing and duration, as well the reasons for the transition and other details. To assess the validity of these data, we conducted systematic comparisons of our self-report data on periods of welfare receipt with records data collected on the study participant's receipt of aid from the county's database used to disburse welfare checks. These comparisons yielded measures of agreement between self-report data and administrative records as high as $80 \%$ when examining whether or not a service episode occurred. While less precision around exact month-to-month comparisons was found, there was no significant bias attributable to substance use status (Wiley and Schmidt, 2003).

Independent variables were selected with an understanding of the many complex factors that give rise to employment outcomes for women on welfare (Bane and Ellwood, 1994; Harris, 1993, 1997; Schmidt et al., 2002). Our analyses include predictors of work readiness, including demographic characteristics, work and educational history, family size, psychiatric distress, and substance use status. We used a standard measure of psychiatric distress based on the 53-item Brief Symptom Inventory (Derogatis, 1992). Psychiatric distress is defined in terms of the total count of psychiatric symptoms that exceeds the gender-based norm for symptom severity. If participants meet the criteria for "caseness" on the BSI's Global Severity Index and/or on two or more of its nine subscales, they are classified as experiencing psychiatric distress.

Substance use is measured at baseline and at each yearly follow-up. Participants are classified as having a substance use-related problem if they meet standard criteria for problem drinking and/or the heavy use of unprescribed drugs during the 12 months prior to the 
interview. Problem drinking is defined by satisfying two or more of the following criteria during the year prior to interview: (a)consumption of five or more drinks of beer, wine, or spirits at one sitting on a monthly basis or more often; (b)at least oneof five alcohol-dependence symptoms; and (c)at least one of five alcohol-related social consequences. Heavy drug use is defined as the unprescribed use of at least one of the following substances on at least a weekly basis during the year prior to the interview: cocaine or crack, amphetamines or crank, sedatives, heroin, other opiates, marijuana or hashish, and psychedelics. Similar measures have been used in numerous prior epidemiological studies of clinical and general populations (e.g., Weisner and Schmidt, 1992, 1995b), including longitudinal studies of welfare recipients (e.g., Schmidt et al., 2002) and women (e.g., Wilsnack, Klassen, Schur, and Wilsnack, 1991).

\section{Data Analysis}

The present analysis is confined to female recipients of TANF who completed the first two waves of longitudinal follow-up, affording a baseline $N$ of 419 cases. Ninety percent of TANF recipients were female, and by virtue of TANF eligibility criteria, all of these women were pregnant or already mothers with children in the home at baseline. After a careful examination of results, we chose to exclude men in the TANF sample from this analysis, given that their experiences with welfare and work differed substantially from those of the majority female population. Throughout, we present weighted results, with unweighted $N$ s. Statistical weights equalize the uneven probability of selection due to nonresponse at baseline and modest attrition at the two follow-up waves as well as adjusting for the oversampling of problem drinkers and heavy drug users.

As a preliminary step, all waves of data on all study participants were concatenated into a single data file representing a continuous record for each individual throughout the study's observation period. In this analysis, we use Cox proportional hazard regression in the STATA Version 7 program, which uses a partial likelihood method of estimation that accommodates sample weights and right censored observations. All other analyses were conducted using SPSS Version 11.5.

The analysis begins by profiling differences in characteristics of work-readiness obtained by substance users and other women on TANF using chi-squares and t-tests to assess statistical differences. The remainder of the analysis focuses on a series of four regression models that are organized in a hierarchical fashion to assess the role of substance use in transitions off of and on to welfare. First, we fit two models that address questions about how substance use impacts transitions off of and out of welfare, focusing on the welfare episode that began at the baseline interview. We begin with a Cox proportional hazard regression that examines the number of months from the initial receipt of TANF at baseline to the first welfare exit. This is followed by a second, standard logistic regression conducted only on those cases that left their baseline welfare episode to examine the odds of leaving welfare for a job versus for some other reason (e.g., due to family reasons such as getting married or moving residences). Our analysis of subsequent transitions back on to welfare parallels the analysis of welfare exits: First, we use Cox regression analysis to examine the number of months from welfare exit to the next reentry on to aid among mothers who experienced an initial exit. This is followed by a logistic regression conducted on mothers who reentered aid to examine the odds of reentering welfare due to job loss versus some other reason. In our analyses of welfare reentry, we use the measure of substance use that is most proximal to the time of welfare exit, when the period of risk for reentry began. 
To help guide the development of these statistical models, we conducted a series of forward stepwise regressions that incorporated a wider range of variables, including all of the independent variables mentioned above plus measures of ethnicity, health status, family structure, age of youngest child in the home, and diagnostic measures of alcohol and drug dependence. This procedure allowed us to develop reduced-form equations in the interest of parsimony in cases where a variable was repeatedly excluded from the stepwise regression analyses. It also guided our selection of substance use measures, given that the results for analyses using alcohol and drug dependence did not differ markedly from those that used the lower-severity measures of problem drinking and heavy drug use.

\section{Results}

\section{Substance Use and Leaving Welfare for Work}

We begin by profiling differences in baseline characteristics of work readiness among welfare mothers who do and do not meet our criteria for substance use. As Table 2 suggests, those who entered welfare with a substance use-related problem are somewhat more disadvantaged with respects to work potential. They are significantly less likely to have a high school degree (including GED) and more likely to report symptoms of psychiatric distress. These initial differences in work readiness point to the need for a multivariate analysis that allows us to assess the effects of substance use independent of other factors that may influence transitions off of aid and into paid employment.

We begin to assess the independent effects of substance use on welfare exits in Table 3, which shows the results of a Cox proportional hazard regression analysis. The hazard ratios shown in the table represent each independent variable's effect with respects to increasing or decreasing the study participant's hazard of exiting welfare from the baseline episode on aid. Given each individual's situation, the event of leaving welfare could have taken place during any wave of follow-up or not at all. The majority, or $65 \%$, of welfare mothers had already left TANF by the end of the 24-month observation period. The regression results show that women who left their baseline episode of welfare tend to be older than those who stayed behind on welfare, with the hazard increasing slightly with each year of age. Having three or more children in the home significantly reduces a participant's hazard of leaving welfare, so that those with more child care responsibilities are more likely to remain on aid. A lack of recent work history also significantly decreases participants' hazard of exiting

Table 3

Cox regression on hazard of a first exit from welfare

\begin{tabular}{lccc}
\hline & Cox regression coefficient & $p \leq$ & Hazard ratio \\
\hline Age (in years) & .026 & .006 & $1.027^{* *}$ \\
No work history in last 12 months & -.368 & .036 & $.692^{*}$ \\
High school graduate & .152 & .360 & 1.164 \\
3 or more children in the home & -.511 & .008 & $.600^{* *}$ \\
Psychiatric distress & .103 & .507 & 1.108 \\
Substance use at baseline & -.051 & .730 & .950 \\
\hline
\end{tabular}

Note. Data are weighted for nonresponse and design. Unweighted $N=305$, Model $\chi^{2}=17.13,6$ d.f., $p<.009$.

$*^{p} \leq .05 ;{ }^{* *} p \leq .01$. 
Table 4

Logistic regression on odds of leaving TANF for a job on the first welfare exit

\begin{tabular}{lccc}
\hline & Logistic regression coefficient & $p \leq$ & Odds ratio \\
\hline Age & -.010 & .637 & .990 \\
No work history last 12 months & -.478 & .225 & .620 \\
High school graduate & .428 & .235 & 1.534 \\
3 Or more children in the home & -.639 & .092 & .528 \\
Psychiatric distress & -.493 & .105 & .611 \\
Time on aid (in months) & -.056 & .037 & $.946^{*}$ \\
Substance use at baseline & .020 & .962 & 1.020 \\
\hline
\end{tabular}

Note. Data are weighted for nonresponse and design. Unweighted $N=207$, Model $\chi^{2}=17.57$, 7 d.f., $p<.014$, Nagelkerke $\mathrm{R}^{2}=.109$.

${ }^{*} p \leq .05$.

welfare. Notably, after controlling for these other predictors of leaving aid, substance use appears to have no relationship to the hazard of exiting welfare.

We further examine factors associated with leaving welfare in Table 4, which shows the results of a logistic regression conducted among those women who had left aid by the end of the 2-year observation period. This model shows factors that influence the likelihood of having a first welfare exit for a job as opposed to an exit for some other reason. In the majority of cases, those who left aid for non-work-related reasons reported family changes that affected their welfare eligibility, such as losing child custody or moving residences. As Table 4 shows, the number of months spent on aid prior to the exit is negatively related to leaving aid for a job, with participants slightly less likely to leave welfare for work the longer they remain on TANF. No other statistically significant results emerge from this analysis, although the effects of psychiatric distress and having three or more children in the home almost approach statistical significance. After controlling on these factors, it is notable that substance use has no statistical relationship with exiting welfare for a job. Indeed, the odds ratio associated with substance use is nearly 1.00 , indicating a strong null finding.

\section{Substance Use, Work, and Returns to Aid}

We next turn the question of whether substance use-related problems impact the capacity of women who leave aid to remain economically independent of the welfare system. We begin by examining characteristics of the jobs obtained by those who left welfare for work. As Table 5 suggests, there appear to be no significant differences in the quality or stability of the jobs obtained by women with a substance use-related problem as compared to those without a substance use-related problem. No statistically significant differences were found between substance users and non-substance users in terms of whether their jobs were parttime or full-time, whether or not their jobs were in a service industry, in estimated annual pay, and in the duration of the job. On the whole, the jobs women obtained upon leaving aid were poorly paid and of a short duration, regardless of whether or not a substance use-related problem was present. More than three-quarters of the participants whose first welfare exit was for a job were no longer working at that job by the 24-month follow-up interview, with most jobs lasting only about 10 months. Median annual pay was low relative to the cost of living in the study site (where the median annual income is over $\$ 70,000$ per year), and many welfare mothers wound up in part-time jobs in service industries. 
Table 5

Characteristics of the jobs obtained upon first welfare exit: Substance using welfare mothers at baseline versus others

\begin{tabular}{lcc}
\hline & Substance abuse & No substance abuse \\
\hline Percent part-time & 18.2 & 10.8 \\
Percent service industry & 45.5 & 32.0 \\
Estimated annual pay (median \$) & $\$ 20,476$ & $\$ 20,800$ \\
Duration of job (average months) & 10.7 & 9.5 \\
Percent no longer in job (as of 24 month interview) & 75.0 & 76.3 \\
Unweighted $N$ & 30 & 58 \\
\hline
\end{tabular}

Note. Data are weighted for nonresponse and design. No statistically significant differences by substance abuse status were found.

Consistent with the overall poor pay and short duration of the jobs obtained by women who left aid, we observed an overall high probability of returning to welfare. Among those who experienced an initial exit from welfare, $44 \%$ had returned by the end of the 24-month period of observation. Table 6 shows the results of a Cox regression analysis that examines factors associated with returns to aid among those with an initial exit. Having a high school diploma has a pronounced effect on decreasing the hazard of returning to welfare. No other factors have a statistically significant impact on the time to welfare reentry. While the association with substance use is in the positive direction, it is not statistically significant.

Table 7 shows the results of a final logistic regression analysis used to examine the likelihood of returning to welfare due to a job loss, as opposed to some other reason, such as a family change. This analysis is confined to those women in the study who had left welfare and reentered within the 24-month window of observation. Women with no recent work history during the 12 months prior to baseline appear less likely to return to aid due to a job loss. No other factors have a statistically significant impact on welfare return. However, the effects of those with three or more children in the home and those without a high school degree almost approach statistical significance. While the effect for substance use is appropriately negative, and larger than in previous analyses, the result is, once again, not statistically significant.

Table 6

Cox regression on hazard of reentering TANF following an initial welfare exit

\begin{tabular}{lccc}
\hline & Cox regression coefficient & $p \leq$ & Hazard ratio \\
\hline Age (in years) & -.031 & .121 & .969 \\
No work history in last 12 months & -.330 & .305 & .719 \\
High school graduate & -.704 & .005 & $.464^{* *}$ \\
3 or more children in the home & .003 & .993 & 1.003 \\
Psychiatric distress & -.121 & .615 & .886 \\
Exited welfare for a job & .331 & .179 & 1.392 \\
Substance use at time of exit & .391 & .154 & 1.479 \\
\hline
\end{tabular}

Note. Data are weighted for non-response and design. Unweighted $N=187$, Model $\chi^{2}=19.88$, 7 d.f., $p<.006$.

${ }^{* *} p \leq .01$. 
Table 7

Logistic regression on odds of reentering TANF due to job loss

\begin{tabular}{lcccc}
\hline & Logistic regression coefficient & $p \leq$ & Odds ratio \\
\hline Age (in years) & -.024 & .487 & .976 \\
No work history in last 12 months & -1.433 & .041 & $.239^{*}$ \\
High school graduate & .841 & .090 & 2.320 \\
3 or more children in the home & -1.061 & .101 & .346 \\
Psychiatric distress & .306 & .517 & 1.358 \\
Time off of aid (in months) & .061 & .202 & 1.063 \\
Substance use at time of exit & -.653 & .244 & .520 \\
\hline
\end{tabular}

Note. Data are weighted for non-response and design. Unweighted $N=116$, Model $\chi^{2}=16.94$, d.f. $=7, p<.018$, Nagelkerke $\mathrm{R}^{2}=.198$.

${ }^{*} p \leq .05$.

\section{Discussion}

This study was motivated by the concern that substance use adversely impacts the welfare and work trajectories of low-income women. While the broader literature on alcohol, drugs, and unemployment has reported some mixed results, studies suggest that substance use is most consistently associated with chronic, episodic, and unsteady employment patterns over time. This led us to hypothesize that the welfare mothers with substance use-related problems in this study would experience unique challenges in moving from welfare to work and that they would be especially prone to difficulties with keeping jobs and remaining independent of the welfare system over time.

The results of our analysis, however, defied these predictions. While factors such as education, work history, and family size consistently predicted transitions from welfare to work and back again, substance use-related problems consistently did not. First, we found no evidence that substance use operates independently as a barrier to work. After controlling on other factors, alcohol and drug use-related problems had virtually no relationship with the time until welfare exit or with the odds of leaving welfare for work. Other barriers to employment, such as having significant child-rearing responsibilities, appeared to be highly consequential in exits from welfare. Interestingly, we also found that the longer a woman spent on aid, the less likely she was to eventually leave welfare for work. This finding may contradict the premise of welfare reform's "work first" philosophy, which presumes that women can be motivated and readied for the labor market through greater participation in TANF's mandatory welfare-to-work programs.

Based on the broader literature, we also expected to find that substance use would have a particularly strong impact on the probability of returning to welfare following a job loss. What we found here, however, was that when women with substance use-related problems left aid for work, the time they spent in their jobs and pay differed little from those of women without substance use-related problems. Regardless of whether or a not a welfare mother had an alcohol or drug use problem, employment following welfare tended to be poorly paid and short-lived, on average lasting only 9 to 10 months. In keeping with this, substance use had no statistically significant impact on the duration of time women spent off of aid or on the chances of returning to aid due to a job loss. It is, of course, possible that we might observe a statistically significant association between substance use and welfare returns by observing welfare mothers over a longer interval of time, after tracking them through multiple welfare exits and reentries. However, we have not as yet 
observed statistically significant associations between substance use and any employmentrelated outcomes. Meanwhile, other factors related to work experience, education, and child-rearing demands appear to be robust predictors of welfare and work trajectories.

On the whole, our results suggest that practical issues, such as having little work experience and substantial parenting demands, are key factors that drive transitions from welfare to work-at least more so than alcohol- and drug use-related problems. While substance use may not independently predict welfare and work transitions, it is associated with some of these practical limitations. Thus, we found that substance users in this study were significantly less likely to hold high school diplomas - a factor that we found ultimately has a substantial impact on the capacity to stay off welfare over time. To the extent that substance use is associated with limitations in work readiness and employment potential it may play a more complex, indirect role by influencing the capacity of welfare mothers to become employed and to remain economically self-sufficient.

The findings of our analysis may also offer some clues into why we observed no effect of substance use on transitions from welfare to work. We found that, for all welfare mothers-regardless of substance use or misuse - the average pay level and duration of the jobs obtained after welfare did not differ. Job opportunities for welfare mothers were largely confined to short-term and poorly paid employment. It may very well be that this labor market context places a low ceiling on the effects that substance use can exert on patterns of employment over time. If all that is open to welfare mothers are low-pay, shortlived work assignments, substance use may have little time to impact work performance and, ultimately, job retention. Alternatively, in circumstances where one can reasonably hold expectations of long-term job tenure and upward mobility, substance use may play a relatively greater role in governing the flow of people in and out of the labor market.

The situation of welfare mothers may, in the end, offer us an extreme case that informs our understanding of the relationships between substance use and employment among women in general. To the extent that the pay and duration of employment opportunities are more limited and constrained for women than men, we may find that substance use has less room to impact job performance and job tenure. Our work on welfare mothers also underscores the importance of family and education as drivers in the employment trajectories of women. Much more so than substance use, the number of the children in the home was a determining factor in transitions off of welfare and may also hamper transitions into work. Furthermore, once off of aid, education appeared to play an important role in keeping women independent of the welfare system. Substance use may, of course, have complex roles to play in shaping the educational attainment and family contexts in which poor women live. For these reasons, the emerging body of research on employment among welfare mothers may offer opportunities to deepen our understanding of the complex ways that substance use impacts work and economic well-being. Our results therefore suggest that interventions to improve the employment prospects of welfare mothers might better emphasize the education and family contexts in which poor women live rather than targeting substance use-related problems alone.

\section{Study Limitations}

An important limitation of this study is that our sample is confined to cash aid recipients in a single county, which may limit the generalizability of results. We took special care to select a large study site-a county of over 900,000 people - that captured the full demographic diversity of the United States and where welfare policies are fairly typical. Rates 
of behavioral health problems and welfare experiences in the WCLS sample are roughly similar to other samples of comparable welfare populations, both at the national and local levels (for comparisons, see Schmidt and McCarty, 2000; Zivot and Jacobs, 2004). Moreover, related work on the WCLS has involved the use of ethnographic techniques to directly observe how welfare-to-work programs and policies targeting substance use are being implemented throughout the study site (for reports, see Dohan et al., 2005; Henderson et al., 2006). Such detail can be used to assess whether our results are applicable to other places where welfare reform policies are being implemented in similar ways.

There is also a high potential for reporting bias in substance use measures, given that study participants may not trust interviewers, fearing that their information could be divulged to welfare system authorities. In an effort to mitigate this problem, we made efforts to match interviewers to the gender and racial characteristics of study participants (see United States National Institute on Drug Abuse, 1985). Study participants were also repeatedly advised that the research team is not affiliated with the welfare department, that participation in the study was voluntary and completely independent of receiving services, and that any information collected would remain confidential from welfare officials. Special provisions were made to clearly distinguish interviewers from welfare department staff and to assure complete privacy during interviews. All study participants gave written informed consent at the outset of the study and provide updated verbal consent prior to each annual interview.

\section{Acknowledgements}

Work on this study was supported by grants from the U.S. National Institutes on Health, National Institute on Alcohol Abuse and Alcoholism P50-AA-05595, R01-AA-13136, and R01-14918. An earlier version of this paper was presented by Ms. Zabkiewicz at the conference Employment and Drug Abuse at the University of Kentucky, April 2005. The authors are grateful to Bridget Fleming and other members of the Welfare Client Longitudinal Study team for assistance with data collection, programming, and development of this manuscript. We also thank the study participants and welfare agencies that have so graciously given of their time to make this research possible and the fieldwork team at the Center for Applied Local Research in Richmond, California, assisted by Mr. Kenny Garron of the Alcohol Research group.

\section{RÉSUMÉ}

\section{L'abus de substance et le travail des mères de l'assistance sociale: des allocations au travail et à l'inverse?}

Nous avons peu de recherche en ce qui concerne l'effet de l'abus de substance sur l'employabilité des mères de l'assistance sociale. Mais l'accent sur la réforme de l'assistance sociale de ramener la main-d'œuvre sur la marché du travail a mis cette question en avant. Utilisant des modèles de hazard proportionel de Cox et la régression logistique dans une étude longitudinale des mères de l'assistance sociale en Californie des années 2001-2003, nous examinons comment l'abus de substance affecte l'habilité à quiter l'assistance sociale et continuer l'independence economique après l'assistance sociale. Alors que l'éducation, l'histoire de travail, et la grosseur de la famille prédisent de façon constante les transitions de l'assistance sociale au travail et à l'inverse, les problèmes de l'abus de substances ne le prédisent pas. Néanmoins, les boulots des mères de l'assistance sociale sont de courtes durées et au rabais, qu'elles abusent l'alcool et les drogues ou non. Nous disputons que si 
le seul boulot disponible aux mères de l'assistance sociale n'est que le travail courte durée, l'abus n'aurait que peu d'impact sur la conservation du boulot. Les limitations de l'étude sont documentées.

\section{RESUMEN}

\section{Abuso de Sustancia y Empleo Entre Madres que Reciben Asistencia Social: $\hat{A}_{\text {¿de }}$ Bienestar Social a Trabajo y Viceversa?}

Tenemos muy poca investigactión sobre el tema de como el abuso de sustancias afecta el obtener empleo entre madres que reciben asistencia social. Pero el énfasis que existe en la reforma de asistencia social, de trancisionar a los recipientes de asistencia social a el sector laboral, ha traido este tema a la luz. Empleando la estadística, Cox riesgo proporcional, y regresión logística en un estudio de longitudinal de madres en California que recibieron asistencia social entre el 2001 y 2003, nosotros examinamos como el abuso de substancias afecta la abilidad de hacer la trancisión de recibir asistencia social a trabajar y de mantenerce economicamente independiente depues de haber recibido asistencia social. Mientras la educación, historial laboral y tamano de familia consistentemente pronostican trancisiones de bienestar social a el trabajo y viceversa, problemas de abuso de sustancias consistentemente no pronostican tal trancisión. Sin embargo los trabajos obtenidos por madres que reciben asistencia social son de corto plazo y mal pagados, aùn cuando estas no abusen de alcohol o drogas. Nosotros argumentamos que si lo unico que esta disponible para madres que reciben asistencia social son trabajos de corto plazo, el abuso de sustancias puede tener muy poco tiempo en afectar su retención en el trabajo. Las limitaciones de este estudio son notadas.

\section{THE AUTHORS}

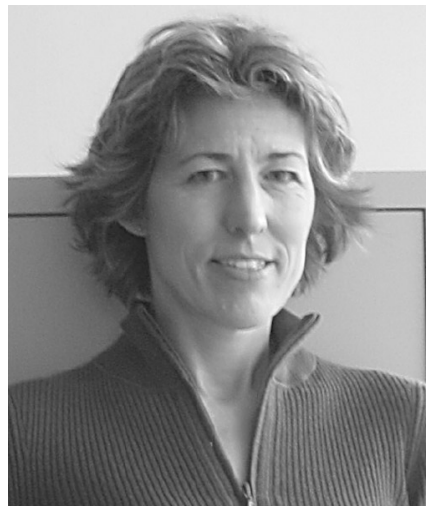

Dr. Laura Schmidt, Associate Professor at UCSF, is a sociologist with master's degrees in public health and social welfare. She is currently principal investigator for the Welfare Client Longitudinal Study funded through the National Institutes of Health and the Robert Wood Johnson Foundation study Implementing Welfare Reform and collaborates on other studies examining access to care, managed care, and stigma in health care organizations. Dr. Schmidt has an extensive publications record in health services research focusing on organizational responses to substance use-related problems, access and utilization. She has consulted for the World Health Organization on studies of the social determinants of health and the cross-cultural applicability of diagnostic concepts related to addiction.

Dr. Schmidt's research program focuses on the social dimensions of health and illness, with an emphasis on the social and organizational contexts in which care is provided, and on substantive health issues, such as addiction, that are heavily influenced by the social environment. Her published studies draw upon a range of social science and epidemiological methods, including longitudinal analyses conducted over long windows of time, cross-sectional surveys and multi-level analyses, as well as historical and ethnographic 
methods. A hallmark of her research is the use of epidemiological approaches to study patient populations, in combination with qualitative and historical research on the health care organizations that provide care.
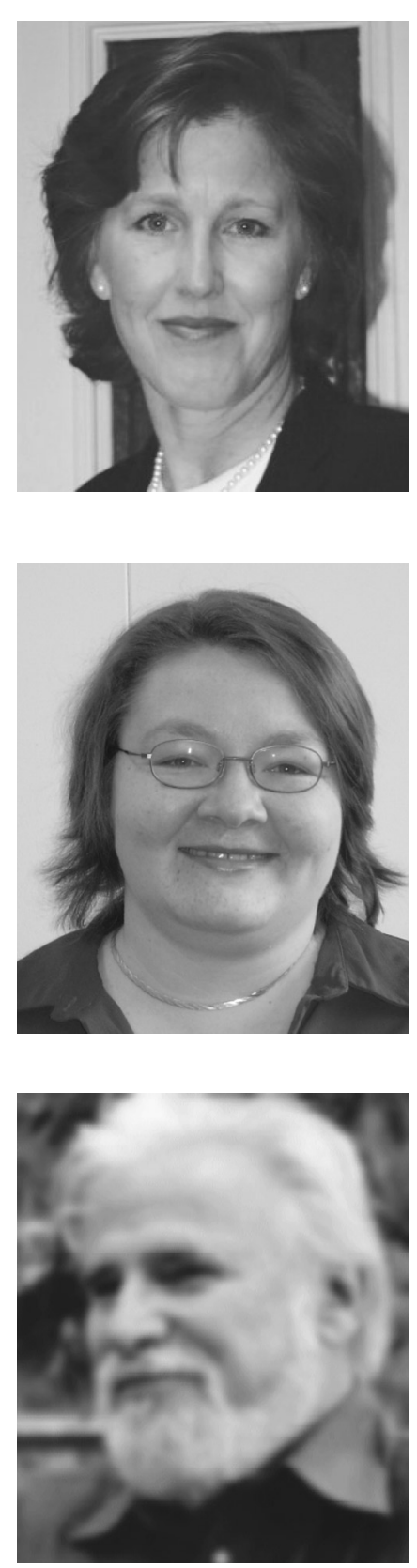

Ms. Denise Zabkiewicz is a doctoral candidate in epidemiology at the University of California, Berkeley, an NIAAA pre-doctoral training fellow and associate scientist at the Alcohol Research Group. Ms. Zabkiewicz has worked with the Welfare Client Longitudinal Study (WCLS) since 1999 and has served in a variety of roles on both the pre- and post-welfare reform study teams. Currently, Ms. Zabkiewicz serves as the principal investigator for the subcontract that manages the fieldwork and data analyses for the WCLS. Her dissertation research draws from the WCLS and examines issues surrounding the mental health and employment experiences of poor women.

Laurie M. Jacobs has been with the WCLS since 2001. During that time, she has collaborated in programming and analysis of study data and managed the longitudinal data collection. She has a B.A. in psychology from Reed College and an M.A. in clinical psychology from the University of Colorado at Colorado Springs. She is currently working on an analysis of the services WCLS clients receive for alcohol, drug, and mental health problems. Her interests also include self-perception as well as stress and coping.

James Wiley is professor of sociology and director of the Public Research Institute (PRI) at San Francisco State University and a senior statistical consultant at the Alcohol Research Group in Berkeley. He is also program director of a Research Infrastructure in Minority Institutions Grant from NIH's National Center for Minority Health and Health Disparities to San Francisco State University. His current work includes writing on the epistemology and ethics of community-based participatory research related to health disparities, research on interventions for victims and perpetrators of domestic violence, and longitudinal studies of the relation between public aid and substance abuse. Dr. Wiley's primary interest is representation of causal processes in theories substance abuse over the lifespan and translation of those theories into testable statistical models for longitudinal data. He also pursues a longterm interest in measurement in the social sciences, particularly in adapting both algebraic and psychometric approaches to the study of responses to questions on opinion surveys. 


\section{Notes}

1. The 1996 Personal Responsibility and Work Opportunity Reconciliation Act (PRWORA, U.S. Public Law 104-193), popularly referred to as welfare reform, brought about a major overhaul of the U.S. welfare system. The PRWORA instituted Temporary Assistance for Needy Families (TANF), a state block grant that established federally mandated work requirements and a maximum 5-year limit to cash aid receipt for clients, as well as new service expectations for local and state welfare systems. The "work first" approach, which predominates in state and local welfare programs, focuses on moving recipients into the labor market as soon as possible, rather than on increasing human capital through longer term investments in education and vocational rehabilitation (Blank and Haskins, 2001).

Welfare reform includes several provisions specific to alcohol and drug use by participants. The legislation empowers welfare agencies to require recipients "to undergo appropriate substance abuse treatment" as a condition of welfare receipt (U.S. Public Law 104-193, sec. 408[b]2[A]v). While this provision stops short of an official mandate to provide treatment for substance use, it encourages agencies to address participants' substance use and substance-related problems that could be a barrier to employment. The reform bill also includes an amendment (sec. 115), sponsored by Republican Senator Phil Gramm, that bans individuals with a felony drug conviction from ever receiving federal aid. Moreover, it includes a provision (sec. 902) that allows states to drug test welfare recipients, although the constitutionality of this provision has been disputed in the courts.

\section{References}

Atkinson, John, S., Whittsett, Donna D., Montoya, Isaaac D., Carroll-Curtis, Tiffany, Brown, Victoria. (2003) Employment and income patterns in a study of a chronic drug using and non-drug using TANF Popationul. Journal of Poverty 7(4):73-91.

Bane, M. J., Ellwood, D. T. (1994). Welfare realities: From rhetoric to reform. Cambridge, MA: Harvard University Press.

Berger, M., Leigh, P. (1988). The effect of alcohol use on wages. Applied Economics 20:1343-1351.

Blank, R., Haskins, R. (2001). The new world of welfare. Washington, DC: Brookings Institution Press.

Brooks, M. G., Buckner, J. C. (1996). Work and welfare: Job histories, barriers to employment, and predictors of work among low-income single mothers. American Journal of Orthopsychiatry 66(4):526-538.

Bryant, R. R., Samaranyake, V. A., Wilhite, A. (2000). The effect of drug use on wages: A human capital interpretation. American Journal of Drug and Alcohol Abuse 26(4):659-682.

Caetano, R. (1991). Correlates of DSM-III-R dependence in treatment and general populations. Drug and Alcohol Dependence 28:225-239.

Claussen, B. (1999). Alcohol disorders and re-employment in a 5-year follow-up of long-term unemployed. Addiction 94(1):133-138.

Danziger, S., Corcoran, M., Danziger, S. H., Heflin, C., Kalil, A., Levine, J., et al. (2000). Barriers to the employment of welfare recipients. In R. Cherry and W. M. Rodgers III (Eds.), Prosperity for all? The economic boom and African Americans (pp. 245-278). New York: Russell Sage Foundation.

Derogatis, L. R. (1992). The Brief Symptom Inventory (BSI) administration, scoring and procedures manual-II. Clinical Psychometric Research, Inc. Baltimore, MI.

Dion, M. R., Derr, M., Anderson, J., Pavetti, L. (1999). Reaching all job-seekers: Employment programs for hard-to-employ populations. Washington, DC: Mathematica Policy Research, Inc. 
Dohan, D., Schmidt, L. A., Henderson, S. (2005). From enabling to bootstrapping: Welfare workers' views of substance abuse and welfare reform. Contemporary Drug Problems, 32(3): 429_ 456.

Edin, K., Lein, L. (1997). Making ends meet: How single mothers survive welfare and low-wage work. New York: Russell Sage Foundation.

Ettner, S. L. (1997). Measuring the human cost of a weak economy: Does unemployment lead to alcohol abuse? Social Science and Medicine 44(2):251-260.

French, M. T., Zarkin, G., (1995). Is moderate alcohol use related to wages? Evidence from Four Worksites. Journal of Health Economics 14(3): 319-344.

French, M. T., Zarkin, G. A., Hubbard, R. L., and Rachal, J. V. (1991). The impact of time in treatment on the employment and earnings of drug abusers. American Journal of Public Health 81(7):904907.

Harris, K. M. (1993). Work and welfare among single mothers in poverty. American Journal of Sociology 99(2):317-352.

Harris, K. M. (1997). Teen mothers and the revolving welfare door. Philadelphia: Temple University Press.

Henderson, S., Dohan, D., and Schmidt, L. (2006). Barriers to identifying substance abuse in the reformed welfare system. Social Service Review 80(June):217-238.

Jin, R. L., Shah, C. P., and Svoboda, T. J. (1995). The impact of unemployment on health: A review of the evidence. Journal of the Canadian Medical Association 153(5):529-540.

Kaestner, R. (1998). Drug use and AFDC participation: Is there a connection? Journal of Policy Analysis and Management, 17(3), 495-520.

Kandel, D., Davies, M., Karus, D., and Yamaguchi, K. (1986). The consequences in young adulthood of adolescent drug involvement. Archives of General Psychiatry 43(8):746-760.

Kandel, D. B., and Yamaguchi, K. (1987). Job mobility and drug use: An event history analysis. American Journal of Sociology 92(4):836-878.

Lahelma, E., Kangas, R., and Manderbacka, K. (1995). Drinking and unemployment: Contrasting patterns among men and women. Drug and Alcohol Dependence 37:71-82.

Metsch, L. R., McCoy, C. B., Miller, M., McAnany, H., and Pereyra, M. (1999). Moving substanceabusing women from welfare to work. Journal of Public Health Policy 20(1):36-55.

Metsch, L. R. and Pollack, H. (2005). Welfare reform and substance abuse. The Milbank Quarterly 83(1):65-99.

Pavetti, L., Olson, K., Pindus, N., Pernas, M., and Isaacs, J. (1996, December 30). Designing welfareto-work programs for families facing personal or family challenges: Lessons from the field. Retrieved July 2003, from http://www.urban.org/welfare/report2.htm

Peck, D. F., and Plant, M. A. (1986). Unemployment and illegal drug use: Concordant evidence from a prospective study and national trends. British Medical Journal 293:929-931.

Schmidt, L., and McCarty, D. (2000). Welfare reform and the changing landscape of substance abuse services for low-income women. Alcoholism: Clinical and Experimental Research, 24(8), 12981311.

Schmidt, L. A., Dohan, D., Wiley, J., and Zabkiewicz, D. (2002). Addiction and welfare dependency: Interpreting the connection. Social Problems 49(2):221-241.

Schmidt, L. A., Weisner, C. M., and Wiley, J. A. (1998). Substance abuse and the course of welfare dependency. American Journal of Public Health 88(11):1616-1622.

Schmidt, L. A., Wiley, J. A., Dohan, D., Zabkiewicz, D., Jacobs, L., Henderson, S., et al. (2006). Changing patterns of addiction and public aid receipt: Tracking the unintended consequences of welfare reform policy. Journal of Health Politics, Policy and Low 31(5):945-948.

Sobell, L., Brown, J., Leo, G. I., and Sobell, M. (1996). The reliability of the alcohol timeline followback when administered by telephone and by computer. Drug and Alcohol Dependence 42:49-54.

United States National Institute on Drug Abuse. (1985). Self-report methods of estimating drug use: Meeting current challenges to validity (NIDA Research Monograph No. 57). Rockville, MD: United States Institute on Drug Abuse, Department of Health and Human Services. 
United States Substance Abuse and Mental Health Services Administration, Office of Applied Studies. (1999). Substance use and mental health characteristics by employment status this is title of the work. 1999. In SAMHSA Administration (Ed.), Rockville, MD: U.S. Department of Human and Health Services. Report A-1 pp. 1-58.

Weisner, C. M., and Schmidt, L. A. (1992). Gender disparities in treatment for alcohol problems. Journal of the American Medical Association 268(14):1872-1876.

Weisner, C. M., and Schmidt, L. A. (1993). Alcohol and drug problems among diverse health and social service populations. American Journal of Public Health 83(6):824-829.

Weisner, C. M., and Schmidt, L. A. (1995a). The community epidemiology laboratory: Studying alcohol problems in community and agency-based populations. Addiction 90(3):329-342.

Weisner, C. M., and Schmidt, L. A. (1995b). Expanding the frame of health services research in the drug abuse field. Health Services Research 30(5):707-726.

Wiley, J., and Schmidt, L. (2003, December). Comparison of records and self-reports data in a cohort of welfare recipients. Paper presented at the Robert Wood Johnson Clinical Scholars Seminar, Health Studies Department, University of Chicago Medical School, Chicago, IL.

Wilsnack, S. C., Klassen, A. D., Schur, B. E., and Wilsnack, R. W. (1991). Predicting onset and chronicity of women's problem drinking: A five-year longitudinal analysis. American Journal of Public Health 81(3):305-318.

Zivot, M., and Jacobs, L. (2004). Technical report 8: Welfare client longitudinal study—Demographic changes in our study county, 1989-2001. Berkeley, CA: Alcohol Research Group. 


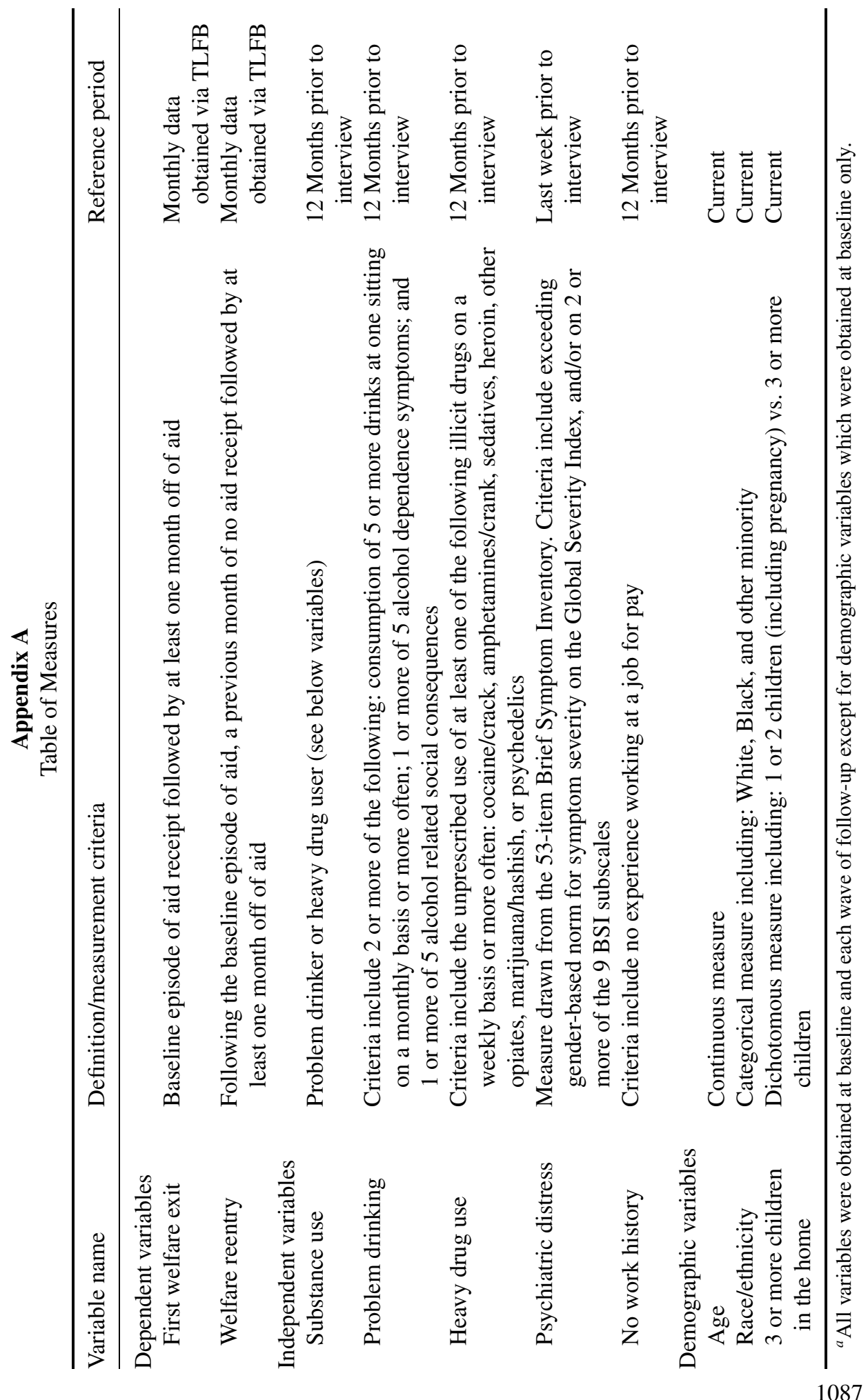


Copyright of Substance Use \& Misuse is the property of Taylor \& Francis Ltd and its content may not be copied or emailed to multiple sites or posted to a listserv without the copyright holder's express written permission. However, users may print, download, or email articles for individual use. 